\title{
Signal Research for Alternative Baltic Navigation System
}

\author{
M. Dziewicki \& J. Młotkowski \\ Maritime Office in Gdynia, Gdynia, Poland
}

T. Stupak

Gdynia Maritime University, Gdynia, Poland

ABSTRACT: In the project R-Mode a navigation system for Baltic Sea is designed. In the range of these actions in summer of 2020 the signal for DGPS base station Rozewie were adopted and measurements on the sea were performer. This experiment is shown in the article.

\section{INTRODUCTION}

The subject of research presented in this paper was "Adaptation of DGPS-PL station devices of the IALA standard", organization of measurements and participation during sea trials of transmission and reception of R-Mode signals and tested in the course of the R-Mode Baltic project in the year 2020. Similar modifications were made at 7 Baltic DGPS stations. They included 3 Swedish stations, 3 German stations, one Polish station and one Danish station on key position Bornholm Island - see the description on the project website: https://projects.interregbaltic.eu/projects/r-mode-baltic-90.html.

Having finalized technical and adaptation works, the team took part in the system tests on land (Rozewie 03-06th August 2020), and then assisted the R-Mode marine tests on Baltic Sea. The route of the Swedish research vessel $\mathrm{m} / \mathrm{s}$ Fyrbyggaren is shown in Fig. 1.

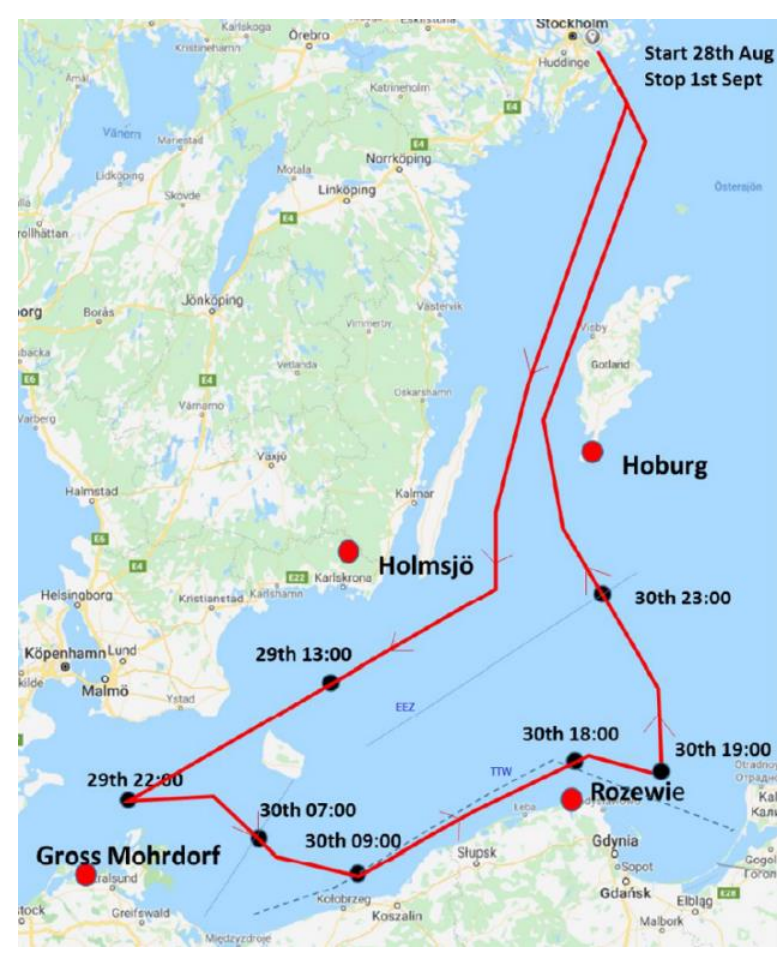

Figure 1. The route of the Swedish vessel $M$ / S Fyrbyggaren 


\section{GENERAL ASSUMPTIONS OF THE PROJECT}

Based on the analysis and research tests of the project in 2018-2020, the requirements of the new R-Mode signal were determined, in particular the linearity of transmitters and the required stability of the frequency and time source needed to meet the assumptions of geographic position error in the new radio navigation system on Baltic Sea. On their basis, requirements were formulated for the parameters of a new type of signal modulator delivered by German partner WSV, and atomic, rubidium type frequency generators - implemented by the Swedish partners.

The propagation analysis performed for the Baltic Sea in 2019 by GRAD (Trinity House - UK) indicated which Baltic stations should be used for testing. The optimization of their geometry (HDOP), i.e. the RMode signal emission points, was aimed at minimizing errors in determining the geographical position of the vessel. As a result of this analysis, Polish DGPS Rozewie and Dziwnów stations were also selected. The project leader (DLR) determined the order of the tests and Rozewie station was selected as a first one. At the same time, it was agreed that the new modulator and time/ frequency generator blocks will be loaned to UMG by project members for carry out land and sea tests, until March 31, 2021.

The R-Mode operation at the Rozewie included the measurement of the new frequency spectrum (band), transmitted power, phase stability of the signals, as shown in Fig. 3. Common procedure of station calibration and coverage range verification were performed prior to marine tests.

During the sea tests, measurements of the signal to noise ratio, the static and dynamic position based on R-Mode emissions were logged and compared to the reference position of the ship.

\subsection{Preparatory works}

Due to the COVID19 pandemic, system readiness was postponed twice, but at that time preparatory works were agreed by teleconference with staff of the project. Measurement of the spectrum of the pure DGPS signal in the air was performed to prepare the reference data after adjustments and R-Mode installation. To minimize possible signal phase changes, a fine tuning of the ATU matching characteristic of the transmitting MF antenna was performed thereafter. The geographic coordinates of the transmitting MF antenna were measured using the RTK technique based on the corrections via radio signal from the Jastarnia reference base station.

Preparatory works covered also:

- Final selection of stations for R-Mode calibration near the Rozewie station,

- Preparation of the assembly station for new RMode modules in the existing DGPS rack.

- Installation of the IT equipment to organize independent remote access via GSM 4G/LTE,

- Installation and adjustment power transmitters with the required linearity and power (Amplidan $157702 \times 100 \mathrm{~W}$ type) at the DGPS Rozewie station, see Fig. 2 - rack of R-Mode located at Rozewie
- Measurement of the reference coordinates of MF R-DGPS antenna using RTK technology,

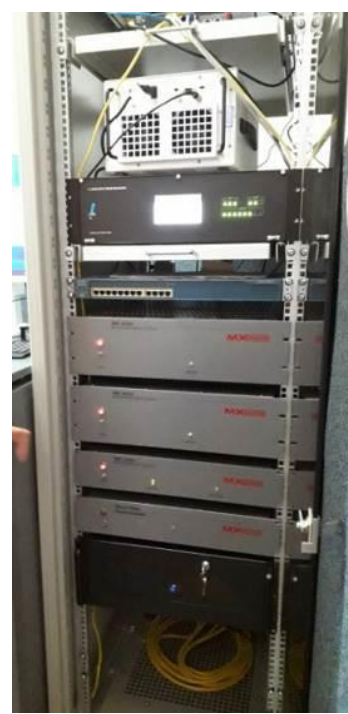

Figure 2. Rack of R-Mode equipment at the top

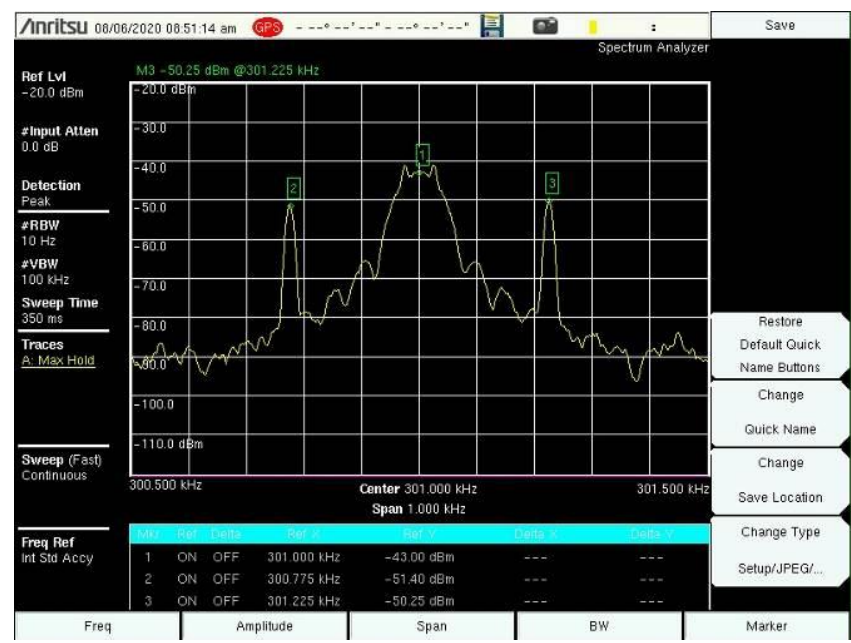

Figure 2. Spectrum of the new R-Mode / DGPS signal in the air, called $2 \mathrm{CW}$ or R-DGPS

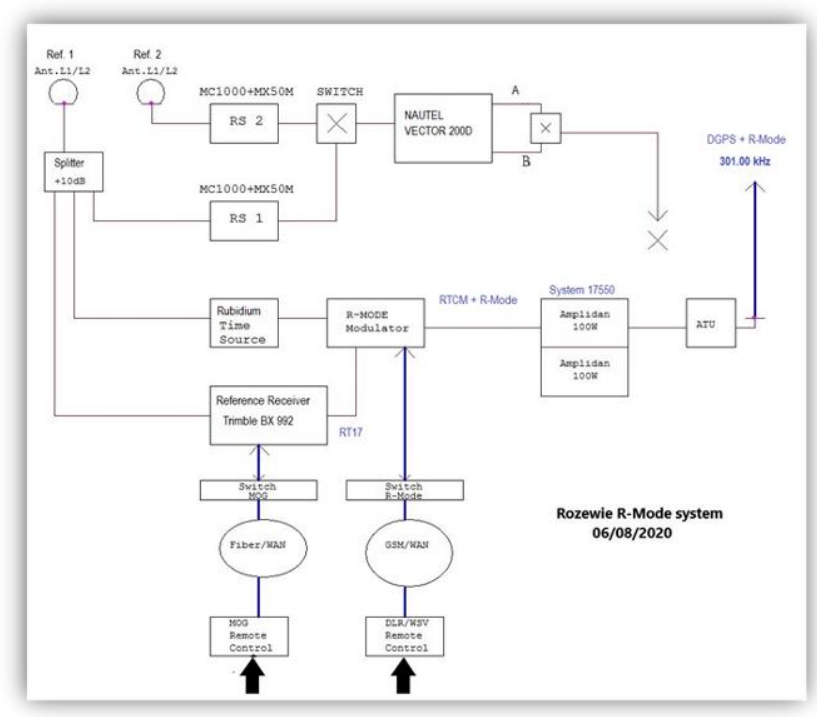

Figure 3. Block diagram of R-Mode modules installed at RDGPS Rozewie. 
The initial commissioning of the new R-Mode $2 \mathrm{CW}$ modulator using the output signal from standard RS1 reference station was unsuccessful, despite contact with the manufacturer and attempts to modify remotely his firmware. Finally, another modern RTK / DGPS receiver was reinstalled and tested. Having done that remote test (via the Internet), new set worked properly with the $2 \mathrm{CW}$ modulator and the rest of the blocks. Final configuration of R-Mode blocks was shown in Fig. 3

\subsection{Field tests}

Several measurements of the signal strength and its characteristics (structure) in the air were carried out. The proper operation was confirmed by testing the spectrum of the DGPS signal and the R-Mode / DGPS signal at the transmitter output, then in the air - Fig. 2. Carriers: L1 $=301.00 \mathrm{kHz}, \mathrm{L} 2=300.775 \mathrm{kHz}, \mathrm{L} 3=$ $301.025 \mathrm{kHz}$.

Field measurements included:

- Determination of the 3D geographic coordinates of the broadcasting antenna (as the R-Mode emission reference point),

- Geographic coordinates of the calibration point, to check the new emission stability and phase measurements.

Both positions were made using the RTK technique and the correction signal from the UMG RTK Jastarnia reference base station at the frequency of $449.025 \mathrm{MHz}$.

The compliance of the new R-Mode signal with the mandatory ITU-R standard was checked as well. The coverage of the signal was checked by data analysis from remote DGPS signal monitors installed in Gdańsk, Northern Port (distance $45 \mathrm{~km}$ ) and in Jarosławiec (distance $120 \mathrm{~km}$ ). The parameters of the signal and the accuracy of the static position did not change, although there was a decrease in signal strength by about 2-3 dB, however a significant increase in the average age of DGPS corrections was noted.

\subsection{Calibration procedure}

Calibration of the station was performed jointly with the German team. A static operation was checked for signal phase stability by setting the R-Mode receiver with a reference antenna having known phase characteristics at the calibration point. Next, using a two-channel oscilloscope, the phase adjustment of the transmitted carriers was made. The comparison of the measured distance (range) from the emission source corresponded to the calculated phase shift of the three carriers of the R-Mode signal $(\mathrm{L} 1=301.00 \mathrm{kHz}$, $\mathrm{L} 2=300.775 \mathrm{kHz}, \mathrm{L} 3=301.025 \mathrm{kHz})$.

\section{MARINE TEST}

The partners from Sweden (SMA) and Germany (DLR, WSV) organized the test cruise around the Southern Baltic. The task of that marine test in the MF band was verification of coverage and accuracy of the dynamic positions. The test of the R-Mode system from the board of the Swedish vessel $\mathrm{m} / \mathrm{s}$ Fyrbyggaren (Gross tonnage: 551) began with installation works in Stockholm and lasted from 28/08 to $01 / 09 / 2020$.

\subsection{Organization of technical assistance}

The task of the Polish team was to ensure the continuous operation of the R-Mode transmitting devices installed at Rozewie, data collection related to the ship's route and distance from the Polish transmitting station. Communication with the team onboard was via satellite telephone and GSM when the ship was in the coastal area. In order to monitor the operation of the Rozewie station devices, the following technical measures were organized:

- a spectrum analyzer with an audible alarm was used for continuous, 24/7, especially at night, analysis of the R-M signal in the air with the alarm option of exceeding the limit parameters (spectrum, amplitude, band). At night, the receiving antenna was mounted on the hotel balcony from the Rozewie side (distance from the transmitter approx. $4 \mathrm{~km}$ ).

- to verify the correctness of DGPS transmission, the Beacon.net software was used, enabling 24-hour online observation of operating screens (SS, SNR, position errors) of R-DGPS remote receivers in the Port Północny and in Jarosławiec.

- the survey vessel's route was recorded by tracking the AIS of the $\mathrm{m} \mathrm{/} \mathrm{s} \mathrm{Fyrbyggaren,} \mathrm{MMSI} \mathrm{=}$ 265289000. At intervals of 2-3 hours, screenshots of the ship's route were taken for documentation of its maneuvers.

- the operation of the Rozewie station transmitter was checked by the readings of the output power (nominal 100W), UPS power status, AC240V local generator readiness, RM modulator status (via GSM network), rubidium clock status of time and frequency.

- communication with the ship took place via the satellite communication system and GSM in the coastal zone (email, telephone, SMS).In particular, Master of the vessel, entering the Polish waters, notified both VTS Świnoujście Traffic and VTS Zatoka Gdańska.

\subsection{Voyage events}

$\mathrm{M} / \mathrm{s}$ Fyrbyggaren entered the signal range of the $\mathrm{R}$ DGPS Rozewie station on August 28th at 12h00 LT, 100 nautical miles $(195 \mathrm{~km})$ from Rozewie at the SOG speed 10.7 knots. The ship was tracked using AIS HELCOM network; her navigational parameters have been logged. Then she sailed along the Swedish coast north of Bornholm, and then around 21 h15 turned south. On 28/08 at approx. 23h50, on the west side of Bornholm, she made a 360-degree loop, and then headed towards Świnoujście. The captain notified VTS by e-mail about his plans to enter Polish waters. Telephone connections were made with VTS operators in Gdynia and Świnoujście, officer on duty informed that the vessel had the appropriate permission to maneuver in the Polish waters. The ship's research team sent an SMS informing that the 
Polish R-Mode station is being received and the signal is at the appropriate SS and SNR levels. Then $\mathrm{m}$ /s Frybyggaren entered the waters of EEZ RP on August 29 at approx. 06h in the morning. Then the ship continued its route along the Polish coast at a lower speed towards the Rozewie traversing it at the distance approx. 10 NM. When the ship entered Bay of Gdańsk on August 30th, in addition to MF R-Mode measurements, also VHF signals were recorded from the VDES broadcasting station in Gdynia port. That VDES base station created by the partner NIT (National Institute of Telecommunication) is collocated to the MOG Monitoring Center tower (RL Gdynia). Here the ship performed a series of maneuvers at different courses along a rectangular route,. She also stopped drifting at a speed close to 0 kn, see AIS track examples in Fig. 4 and Fig.5.

During the final phase of these tests, the Polish team was notified by the call phone from the ship about suspected drift of the R-Mode modulator clock. Inspection activities were undertaken at Rozewie station on 31/8 early morning. All the indicators of the atomic clock, and in particular the signal from the GPS antenna, were correct. The transmitter power stability and set-up of the reference receiver have been tested. Finally, the UMG was informed that the source of the error was found in the set-up of onboard post-processing unit.

\section{MARINE TEST RESULTS}

Timing of the ground installations and the voyage itself were threatened and modified by the COVID19 pandemic. The technical assistance was provided to ensure that the cruise prepared with a great expense of effort and resources of the project will take place without technical disturbances. During the tests, RMode devices of the modified DGPS Rozewie station were operating properly, what was confirmed by messages from the vessel as well as conversations carried out during and after the cruise. Some doubts that arose during the course of the process were clarified on an ongoing basis. In view of the very limited number of stations (7) adapted to broadcast a new signal, it was not possible to risk "falling out" of even one, because it would disturb the required geometry of signal distribution in the South Baltic.

Although all data from the dynamic test has not been processed yet, the forecasted signal range parameters (SS, SNR), the geometry parameters of selected stations (HDOP) have been confirmed and the possibility of determining the ship's position based on the MF band signals with the predicted accuracy has been demonstrated in practice.

\section{CONCLUSIONS BY THE END OF 2020}

On September 14th, a project partner's teleconference initiated by the DLR was held, during which the initial test results of the marine MF systems with the participation of the DGPS Rozewie station were presented. This was the first marine test performed within EU waters, and one of the first on the globe. The obtained results showed that the system operation can be initially assessed as positive. The principle of operation of R-Mode and the predicted accuracy of positioning were verified and confirmed. The operation of MF transmission was stable. Thanks to practical tests some refinement was proposed, but it does not require supervision greater than standard DGPS. Due to the fact that only preliminary results of measurements lasting 5 days were announced, it is too early to provide detailed results of collective studies of both individual parameters and their behavior over time.

Due to conclusions of IALA workshop (Edinburgh 2020) on the future of DGNSS systems, the R-Mode system can be the successor of ground based differential systems (DGPS, DGlonass etc.) and may became the real backup to GNSS itself.

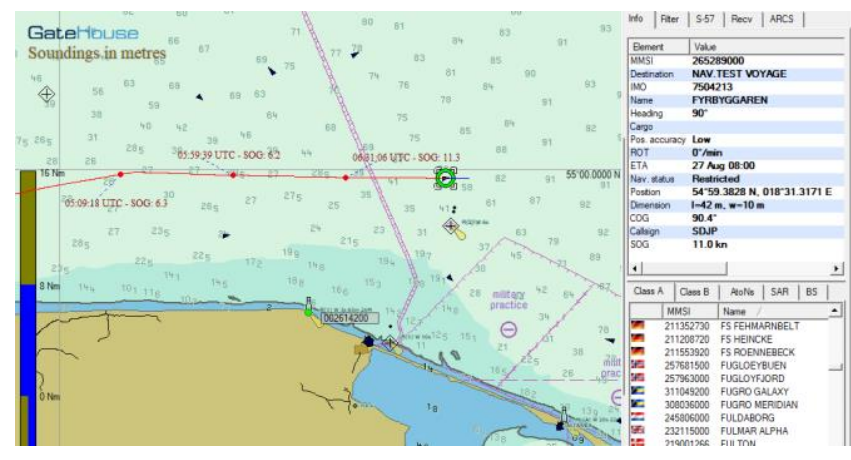

Figure 4. Track of $\mathrm{m} / \mathrm{s}$ Fyrbyggaren passing R-DGPS Rozewie

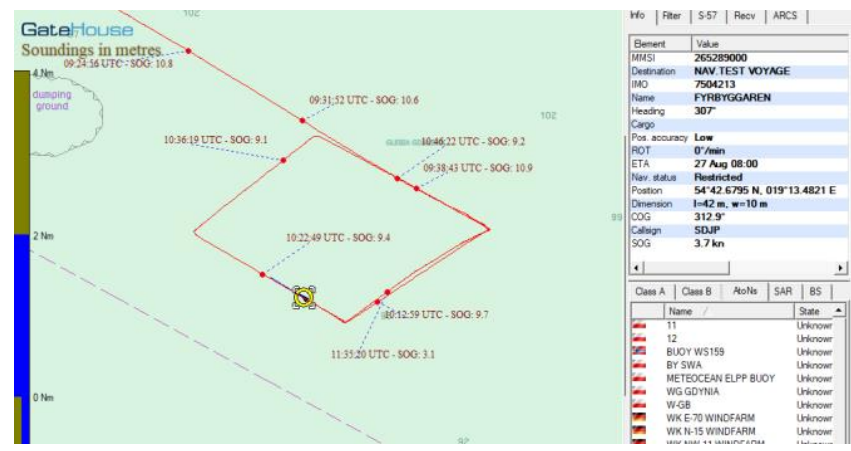

Figure 5. Maneuvers during the VDES test on Gdansk Bay

\section{REFERENCES}

1. Adaptation of DGPS-PL station devices of the IALA standard, organization of measurements and participation in sea trials of transmission and reception of R-Mode signals. Gdynia Maritime Office, 2020

2. Dziewicki M, Ledóchowski M, Stupak T.: Badanie zasięgu i dokładności Krajowego Systemu Radionawigacyjnego DGPS, Transcomp Zakopane, Technika Transportu Szynowego 9/2012 nr 437 str. 4165-4173 (na CD).

3. Dziewicki M, Ledóchowski M, Stupak T.: Koncepcja monitorowania Krajowego Radionawigacyjnego Systemu DGPS/RTK z funkcją generowania poprawek przez stacje monitorujące. Przegląd Telekomunikacyjny Rocznik LXXXV nr 11/2013 str. 1652 -1655 